\title{
REFORMA AGRÁRIA E MEIO AMBIENTE: INTERFACES DA FUNÇÃO SOCIAL E AMBIENTAL DA TERRA
}

\author{
MÔNICA COX De BRITTO PEREIRA'
}

Universidade Federal Fluminense

\section{Introdução}

Nos últimos dois séculos evidenciaram-se grandes mudanças na relação sociedadenatureza. Historicamente muitas sociedades desenvolveram-se em convivência com a natureza, de forma que suas intervenções se davam em consonância com a dinâmica e os ciclos da natureza. As raízes do teocentrismo e do antropocentrismo, reforçadas pelo cientificismo, foram levando à uma separação entre ser humano e natureza, e à uma relação de dominação e de tentativa de controle da dinâmica da natureza.

Vai-se constituindo um processo de dicotomia e de separação ser humano-natureza. Assim a forma como as sociedades foram se organizando levou à uma enorme transformação dos ambientes, a uma valorização desta racionalidade como modo social hegemônico, bem como a desvalorização e a pressão sobre as populações que se organizam sob outras racionalidades, tais como, indígenas, agricultores, e pescadores, que em geral possibilitaram manter os ambientes mais conservados. Conforme essas áreas foram sendo utilizadas para projetos econômicos e para a viabilização do almejado progresso e desenvolvimento, a degradação ambiental foi se dando a passos largos, com destruição ecológica e exclusão social. Foram assim se fragmentando os ecossistemas e os agroecossistemas mais antigos, tradicionais no manejo mais articulado à dinâmica ecológica, e foram se reordenando os lugares e territórios. Dessa forma, também foram se desarticulando os estudos no campo da ciência, divididos em biológicos ou sociais. Como exemplo temos, a Ecologia Humana, a Antropologia procurando resgatar a importância desse conhecimento do manejo ecológico, a Biologia

\footnotetext{
${ }^{1}$ Doutoranda em Desenvolvimento, Sociedade e Agricultura pelo CPDA/UFRRJ.
} 
da Conservação procurando entender os efeitos na fragmentação de ecossistemas sob uma perspectiva multidisciplinar, a Geografia procurando tratar de forma integrada, como assim é a relação sociedade/ser humano-natureza, e a Agroecologia que tem como princípios conjugar a restauração ecológica, a diversidade cultural, o etnoconhecimento e a participação comunitária.

\section{A Ação Intervencionista do Estado no Vale do Rio São João, RJ.}

Desde o início do século as atividades agrícolas predominantes dos municípios de Casimiro de Abreu e Silva Jardim, RJ, foram café, cana, arroz, extração de madeira, lenha, banana e lavoura. A região do Vale do São João na década de 1970 foi alvo de ações governamentais, com a construção da Barragem de Juturnaíba, de canais para drenagem da região, da implantação de projetos agropecuários de monocultura de arroz com o uso de insumos químicos, agrotóxicos e irrigação (CUNHA, 1995 e BINSZTOCK, 1993, 1998).

A região à essa época já contabilizava grande degradação de seus ambientes hídricos e da biota terrestre. Warren Dean (1996) relata que a espécie do mico leão dourado foi apreciada desde os tempos da colônia, tendo sido capturado por criadores e exportados para a Europa. No fim dos anos 60, restaram algumas centenas, em virtude também da transformação de grande parte da Mata Atlântica da Baixada Fluminense. Os zoológicos de outros países contribuíram para esse declínio, uma vez que haviam comprado micos por todo o tempo em que o tráfico ainda era legal.

Um relatório na década de 1970 do Museu Nacional levou a apoiar a preservação da espécie. O anúncio de criação da reserva biológica em 1971 incitou os ocupantes do seu interior a vender toda sua madeira. Hoje a Reserva Biológica de Poço das Antas é uma área de mata de cerca de 5000 ha e desde a sua criação tem em torno de $35 \%$ de área degradada. Há trechos de mata que foram alagados pelas obras no rio São João e na Lagoa Juturnaíba, trechos de cobertura de gramíneas e de regeneração interrompida pelo fogo.

Desde o início é alvo de degradação por inúmeras intervenções, principalmente por concepções que não incorporam o aspecto socioambiental, e pelo contrário, baseiamse numa lógica de degradação e empobrecimento da vida. Os projetos de drenagem e de construção de canais, de represamento da lagoa, resultaram em alteração do solo, da rede hídrica, da vegetação e da biodiversidade como um todo. Também os projetos agropecuários que combinavam plantio de monocultura de arroz, de cana, e gado, com o uso de agrotóxicos, pastagem exótica, retirada das árvores e utilização do fogo como prática, levaram a esterilizar o solo, matar a fauna, a vegetação e alterar significativamente a ecologia local.

Nesse sentido, a reserva biológica carece de ampliar sua unidade ecológica e poder ter mais intercâmbio através da recuperação e transformação de áreas degradadas 
dentro e fora da reserva. Poder ir além da concepção de uma ilha de proteção ambiental e ter o foco na recuperação do mosaico da vegetação na região como um todo, de forma a ampliar a diversidade de organismos vivos, a disponibilidade de água, a riqueza do solo, a riqueza da vegetação e de interações entre fauna, flora e ser humano e da dinâmica ecológica como um todo. Desta forma, resulta que o ambiente amplia o seu grau de conservação, necessitando cada vez menos de intervenções reducionistas e pontuais, levando a valorizar mais as atividades daqueles que façam o manejo da diversidade de espécies a partir de uma racionalidade ecológica e tenham um impacto positivo no ambiente.

Qualquer unidade de conservação hoje sofre do efeito de borda (PRIMACK, 2001), afinal essa mata deixou de ser contínua encontrando-se fragmentada (KAGEYAMA, 2003) e muitas vezes deixou de ser manejada por intervenções harmoniosas, tais como, os ciclos agrícolas com uso das práticas de agricultura itinerante com pousios de regeneração a longo prazo. Conforme a Ecologia e a Biologia da Conservação, as unidades de conservação são um caso particular de fragmentos de habitat (FERNANDEZ, 2000) e há reflexões importantes quanto às precupações daí resultantes. Quammen (1996, apud FERNANDEZ, 2000) faz uma afirmativa incisiva: "Assim como ilhas, (os parques nacionais) são lugares onde as espécies vão para morrer." A reserva como ilha está fadada a ter efeitos diversos a partir da sua borda. Essa visão da unidade de conservação isolada pode ser corroborada por formas de gestão que a reforce como ilha, não potencialize a dinâmica ecológica e portanto não consega otimizar ou priorizar, de fato, a conservação ambiental, levando o que Diegues (1996) chama de Crise da Conservação, e por sua vez, reforce uma visão excludente da conservação.

\section{O conflito agrário e ambiental.}

Estão localizados no entorno da Reserva Biológica de Poço das Antas no município de Silva Jardim, três assentamentos e um acampamento (Quadro I). O Assentamento Aldeia Velha está situado próximo da BR 101, estando assim separado da reserva por esta rodovia, foi criado em 1981 em terras desapropriadas como parte das ações para criação da Reserva Biológica, com intuito de trazer famílias retiradas da área delimitada como reserva biológica. O Assentamento Cambucaes está separado da Reserva Biológica pelo Rio São João, foi criado em 1995, por iniciativa do INCRA para assentar trabalhadores rurais sem terra acampados em 1993 em Macaé e que permaneceram acampados na Fazenda Cambucaes até o assentamento sair. O Assentamento Sebastião Lan está separado pelo canal do São João em trecho retificado após a barragem de Juturnaíba e o Acampamento Sebastião Lan, pelo canal do Aldeia Velha. Ambos, parte da ocupação de trabalhadores rurais sem terra organizados pelo MST em junho de 1997, uma das fazendas (Fazenda Sobara) foi desapropriada primeiramente 
e assentaram-se 33 famílias no Assentamento Sebastião Lan 1. O Acampamento Sebastião Lan 2 se mantém na área do brejão, sob posse do INCRA, nos limites da Fazenda Arizona, porém o órgão está impossibilitado até o presente de realizar o assentamento por completo.

\begin{tabular}{|c|c|c|c|c|c|c|}
\hline $\begin{array}{l}\text { Ano de } \\
\text { criação do } \\
\text { projeto }\end{array}$ & $\begin{array}{l}\text { Projeto de } \\
\text { Assentamento }\end{array}$ & Município & \begin{tabular}{|l}
$N^{\circ}$ de \\
famílias
\end{tabular} & \begin{tabular}{|ll} 
Data & do \\
ato & de \\
criação &
\end{tabular} & $\begin{array}{l}\text { Área } \\
\text { (ha) }\end{array}$ & \\
\hline 1981 & Aldeia Velha & \begin{tabular}{|l|} 
Silva \\
Jardim
\end{tabular} & 41 & $08 / 06 / 81$ & 362 & $\begin{array}{l}\text { Decorrente de criação para } \\
\text { reassentamento dos } \\
\text { moradores das fazendas doadas } \\
\text { para a criação da reserva. }\end{array}$ \\
\hline 1995 & Cambucaes & \begin{tabular}{|l|} 
Silva \\
Jardim
\end{tabular} & 103 & $28 / 12 / 95$ & 1.636 & $\begin{array}{lr}\text { Decorrente de ocupação realizada } \\
\text { em Macaé na fazenda Severina; } \\
\text { Incra disponibliza } & \text { área } \\
\text { desapropriada da } & \text { fazenda } \\
\text { Cambucaes em } 1995 . & \\
\end{array}$ \\
\hline 1999 & Sebastião Lan & \begin{tabular}{|l|} 
Silva \\
Jardim
\end{tabular} & 33 & $26 / 07 / 99$ & 520 & $\begin{array}{l}\text { Decorrente de ocupação realizada } \\
\text { em junho de } 1997^{1} \text {, uma parte } \\
\text { das famílias é assentada em } \\
\begin{array}{l}\text { Assentamento Sebastião Lan } \\
\text { gleba I. }\end{array}\end{array}$ \\
\hline \begin{tabular}{|l|} 
Ano de \\
ocupação
\end{tabular} & Acampamento & Município & \begin{tabular}{|l|} 
No de \\
famílias
\end{tabular} & \begin{tabular}{|l|} 
Data da \\
Ocupação
\end{tabular} & $\begin{array}{l}\text { Área } \\
\text { (há) }\end{array}$ & \\
\hline 1997 & $\begin{array}{l}\text { Acampamento } \\
\text { Sebastião Lan } \\
\text { gleba II }\end{array}$ & \begin{tabular}{|l|} 
Silva \\
Jardim
\end{tabular} & 82 & $21 / 06 / 97$ & 1466 & $\begin{array}{l}\text { Brejão }^{2} \text { área anteriormente em } \\
\text { litígio entre Incra e pretenso } \\
\text { proprietário. }\end{array}$ \\
\hline
\end{tabular}

Fonte: Incra, RJ, 2002.

Quadro 1. Assentamentos e acampamento no entorno da Reserva Biológica Poço das Antas, Silva Jardim, RJ.

Sendo a Reserva Biológica de Poço das Antas uma unidade de conservação de proteção integral (BRASIL, 2002), existem assim, proibições da presença humana dentro da reserva ${ }^{4}$, bem como normatização ambiental para o entorno da reserva com

\footnotetext{
${ }^{2}$ A ocupação primeiramente ocorre em trecho de solo drenado pela obras em torno da canalização do Rio São João e represamento da Lagoa de Juturnaíba, área acusada de grilagem, que foi desapropriada e 33 famílias assentadas.

${ }^{3} \mathrm{O}$ brejão refere-se à área alagada e drenada com a canalização do Rio São João, quando muda-se o curso do Rio Aldeia Velha passando a água a seguir pelo canal de Aldeia Velha, tendo sido o leito natural do R. Aldeia Velha abandonado desde então. O brejão foi então grilado por fazendeiro que "mexeu com os limites" de sua fazenda, Faz. Arizona, antes até o leito do Rio Aldeia Velha, agora com o limite alterado até o canal de Aldeia Velha.

${ }^{4}$ As populações foram retiradas quando da criação da reserva (criada em 1974), e fazendeiros desapropriados. Foi criado um projeto de colonização, Aldeia Velha (1981), com intuito de abrigar pessoas desalojadas das fazendas desapropriadas, o que não se realizou completamente.
} 
restrições ambientais para atividades humanas. O conflito vem se dando por meio de litígios ambientais na área, conduzidos na forma de ações civis pública ${ }^{5}$ propostas contra o INCRA, por AMIRIO ${ }^{6}$ e Ministério Público Federal, que demandam a não concretização de assentamento na área do Acampamento Sebastião Lan. Para que o assentamento seja criado é preciso o encaminhamento do TAC, um termo de ajustamento de conduta entre as partes.

A agência do IBAMA referente à reserva biológica no local entende que o assentamento pode configurar um dano ambiental, de proporções irreversíveis e prejuízos irreparáveis ao patrimônio ambiental, pois que o assentamento é uma ameaça. Pressupõe a utilização intensiva e maciça da terra. Concebem o impedimento do assentamento como uma ação preventiva, a fim de evitar uma provável degradação ambiental. Ressaltam que com o aumento da população com o assentamento, tornase provável o aumento do impacto ambiental. Lêem a presença humana na área como ação antrópica, visto que a concepção de natureza é de uma natureza virgem, sem gente, para ser então natureza selvagem, deve ser intocável, qualquer ato ou relação configuram necessariamente uma degradação ambiental. O ser humano é visto sempre fora da natureza.

Outro ponto é a necessidade de cerca de 50ha para cada família de micos, espécie central da política da reserva, o que leva à necessidade de expandir a área da reserva para abrigar famílias novas do primata. Nesta visão não se considera a possibilidade dos animais conviverem com as áreas habitadas pelo homem, entendendo que os animais precisam na sua totalidade estar abrigados na reserva cercada. Dizem também haver competição entre a espécie humana e essa espécie de primata ameaçada de extinção e que a presença humana é um risco ambiental, pois coloca em risco o habitat e a vida do mico. As ameaças listadas são: incêndios, caças, captura de animais, atividades passadas de obras do $\mathrm{DNOS}^{7}$, desmatamento, extrativismo vegetal.

Posições contrárias do INCRA explicam que ao assentar é que se permite normatizar. Os estudos a se realizar para o licenciamento ambiental pelo órgão ambiental, permitirão qualificar as atividades compatíveis com a reserva, utilizando-se, então, de parâmetros ambientais para as áreas de assentamentos rurais.

Em função da relevância ambiental dos municípios de Silva Jardim, RJ e Casimiro de Abreu, RJ nos quais projetos de assentamentos de reforma agrária criados estão localizados em zona de amortecimento da Reserva Biológica Poço das Antas, em área caracterizada como remanescentes de Mata Atlântica de baixada em fragmentos

\footnotetext{
${ }^{5}$ Os litígios ambientais dividem-se, ao menos, em duas categorias: 1) aqueles encaminhados por meio de ação popular, em que o autor é um cidadão; 2) aqueles conduzidos na forma de ação civil pública, em que o polo ativo da ação é constituído, principalmente, por grupos organizados da sociedade civil, por órgãos do Estado, ou pelo Ministério Público (Fuks, 2001).

${ }^{6}$ Associação dos Amigos do Rio São João, organização não governamental criada com a finalidade de proteção do Rio São João na década de 70.

${ }^{7}$ Departamento Nacional de Obras de Saneamento.
} 
e manchas de regeneração, bem como, a existência de ação civil pública impedindo a realização de assentamento de reforma agrária na região, celebrou-se uma Cooperação Técnica MDA/INCRA-RJ e MMA/IBAMA-RJ em 2002. A cooperação teve como objetivos o desenvolvimento de ações para a convivência harmoniosa de assentamentos de reforma agrária e a conservação do ecossistema da Rebio de Poço das Antas e seu entorno. Com este fim foi criado um grupo de trabalho para promover a cooperação técnica na gestão da questão ambiental dos projetos de assentamento de reforma agrária no entorno da Reserva Biológica de Poço das Antas, S. Jardim, RJ. O Grupo de Trabalho ECOSOCIAL ${ }^{8}$, criado pela UFF em 2001 para realizar um laudo sobre a questão referida, passa a coordenar a Cooperação Técnica IBAMA - INCRA 9 .

\section{Convivência entre reforma agrária e proteção ambiental: há viabilidade ambiental de assentamentos de reforma agrária?}

As áreas de amortecimento de unidades de conservação restritivas, como a Reserva Biológica, são de grande importância ecológica. É preciso considerar como um reduto importante para a biodiversidade, bem como, pela proteção de espécies em extinção. Os remanescentes de vegetação em áreas de ecossistemas tropicais são importantes para se planejar a conectividade entre as áreas de vegetação arbórea plantada, as áreas degradadas a serem restauradas, de forma que se torne efetiva a proteção da biodiversidade, a ampliação de habitats, a ocorrência das diferentes espécies na região como um todo e não apenas pontualmente (KAGEYAMA et al, 2003). São esses aspectos que são fundamentais de se conjugar com os projetos de assentamentos rurais.

A caça é muitas vezes levantada como uma possível pressão sobre o ambiente com a presença dos trabalhadores rurais. A caça vem sendo minorada na região do entorno da reserva e pode ser controlada indiretamente pela presença na área das famílias, dos lotes habitados e assim mais protegidos do que anteriormente, em que as áreas de acesso à reserva biológica estavam desabitadas e sem postos de fiscalização. Historicamente os fazendeiros da região tinham como prática frequente a caça. Há também áreas, no limite com Silva Jardim, em que a navegação em pequenas embarcações pelo Rio São João permite adentrar em pontos próximos ou até mesmo dentro da reserva, tendo a presença também de pessoas de fora. As comunidades rurais do entorno da reserva biológica não tem acesso facilitado à reserva, pois a

\footnotetext{
${ }^{8}$ Portaria UFF - Gabinete do Reitor no 29599, 2001-2003.

${ }^{9}$ Os quatro professores membros do GT Ecosocial/UFF foram designados para coordenar o grupo de trabalho da Cooperação Técnica IBAMA-INCRA e realizar um laudo multidisciplinar, apresentado em reunião final desta cooperação técnica no dia 17 de setembro de 2002 na Faculdade de Direito/UFF, ver UFF-GT ECOSOCIAL (2002).
} 
maioria não possui embarcação, visto que são descapitalizados.

Mazzeto e Cavallini (2002) sinalizam que em médio prazo o envolvimento e a mobilização comunitária junto com programas dos órgão públicos diretamente envolvidos, podem ser mecanismos importantes para coibir e transformar a realidade da caça, além do apoio a programas de produção, que podem viabilizar as pequenas criações, prática comum na pequena produção familiar, e garantir, assim, a subsistência das famílias. Diegues (1996) também indica a mobilização da população como estratégia importante na perspectiva da sustentabilidade.

O corte de madeiras por pessoas de fora da área, também pode ser minorado pela ocupação da região por famílias de agricultores. O IBAMA tem registrado que o desmatamento no entorno já não é o maior problema comparado com o fogo. A mudança de uma área anteriormente de fazenda, onde a prática do desmatamento, do fogo para se colocar pastagem exótica do "status" de se ter um pasto "limpo", para uma área de pequena agricultura familiar, aonde passa-se a manter árvores, incorporar frutíferas e outras arbóreas, manter a paisagem mais diversificada e heterogênea, considerandose que a árvore é necessária e as funções ambientais das florestas também, é um salto ecológico. Amplia a conservação. Anteriormente as práticas no entorno não tinham uma valorização ambiental das terras, é o que sinaliza um acampado do entorno da reserva biológica:

O povo aqui quase tudo faz as cercas deles com madeira daqui, do chão!! Então foi desmatando... ele desmatou, preparou a área, depois ele drenou tudinho e começou arrendando e ganhando dinheiro em cima dos arrendatários, até a gente aparecer aqui, prá dar um fim nesse ganho que ele tinha aí! (Acampado de Sebastião Lan gleba II, 2002)

Binsztock (2001) sinaliza que na região do vale do São João, contraditoriamente, é o grande capital na terra e o seu fracasso que permitem a ascensão da pequena produção em espaços, anteriormente ocupados pela grande propriedade rural, e agora ocupados por movimentos sociais rurais. Essa região foi parte das últimas áreas em que se implementou a intervenção do Estado com fins de saneamento, noção entendida à época como transformação das áreas alagadas, consideradas insalubres, em áreas drenadas. Nesse sentido, as terras foram sendo valorizadas para uso em grandes empreendimentos agropecuários, que não lograram sucesso, fruto das próprias características do solo e do ambiente, cuja complexidade ecológica não teve as respostas esperadas através da tecnologia utilizada. Projetos agropecuários fracassaram e as terras foram ocupadas pelo movimento social, com interesse em produzir lavoura nas terras em questão, como bem retrata o antigo arrendatário das terras da fazenda Arizona e hoje acampado nas mesmas terras:

O brejão já foi floresta alagada. Uns 40-60 cm de cinza queimada em áreas 
não mexidas depois. Pra reflorestar precisa de muita gente pra tomar conta, pessoas com interesse de terra, e não terra pra negociar. Assim o assentamento pode funcionar. (Acampado de Sebastião Lan gleba II, 2002).

A região em questão é área de distribuição do mico leão dourado Lenthopithecus rosalia, espécie ameaçada de extinção endêmica do RJ. Hoje em função da reprodução em cativeiro e do manejo combinado ex-situ e in-situ, há animais sem habitat, além de problemas na população núcleo localizada na Reserva Biológica, com questões de consanguinidade na espécie.

Um primeiro aspecto a se considerar é que a reserva, mesmo que estivesse harmonizada com o seu entorno, tal como é hoje, não ofereceria condições ecológicas para um resultado e um status de conservação da espécie satisfatório. Conservar o animal, é preciso conservar mata. No entorno existem fazendas com grandes extensões de pastagens com uso de exóticas e fogo periódico, não são compatíveis nem podem potencializar a dinâmica do ecossistema local, ao contrário, é um passagem abrupta sem transição nem tamponamento da mata para o pasto, não fornece o habitat para o primata nem para outras várias espécies. A racionalidade de grandes fazendas prioriza o econômico, a renda e valorização econômica da terra. Nos depoimentos abaixo, percebemos que a racionalidade da pequena produção, por outro lado, incorpora o ecológico, há uma relação de convivência e reciprocidade com a natureza:

Evito mexer nas minas d'água, nessas grutinhas. O mato que tem eu deixo porque é ele que segura a água. Esses miquinho anda tudo aí, come as frutas, tai à gente não mata. Meu negócio é trabalhar conforme a senhora chegou aí e viu, eu tô colhendo meus negócios... (Assentado de Cambucaes/Olhos d'Água, 2002).

Por que uma árvore pra meu gosto é uma vida, pra mim é um alivio uma árvore e uma sombra tão gostosa, né? E a natureza, as árvores, os bichos, os micos também, tem que conviver com ele. Eu acho que o mico, a gente tem que ter o mico mas tem que ter a pessoa convivendo com o mico, não tem? Por que ele vem aqui. Eu acho muito importante. (Acampada de Sebastião Lan gleba II, 2002).

Um segundo aspecto a salientar, é a conservação de mata considerada como intocada, com suposições de que necessariamente projetos de assentamentos rurais significam um processo que levará a impactos negativos para a proteção ambiental e para a conservação da biodiversidade. É assim, ter como base uma visão de que o processo de Conservação Biológica deve, obrigatoriamente, excluir as comunidades humanas junto à essas áreas. As atividades agrícolas de âmbito familiar conviveram historicamente com populações diversas de micos leão, quando a espécie estava de 
fato em liberdade e com o fluxo gênico pleno.

O que levou à sua destruição? Quem são e quais são de fato as possíveis ameaças? É preciso perguntar que comunidades, que atividades, que modelos aí consideramos? E quais são os impactos positivos nesse processo que podem beneficiar, a longo prazo, a conservação da biodiversidade?

É preciso sublinhar que somente a preservação, focando-se apenas a reserva, ou então somente a produção, focando-se apenas os assentamentos, não oferece garantia de sustentabilidade. É preciso conjugar as duas faces, integrando-se numa perspectiva mais ampla, e acima de tudo sustentável. Esse é o novo paradigma em questão.

A Agroecologia é um campo de conhecimento e uma estratégia para a sustentabilidade: planeja e entende produção e conservação como uma só unidade, portanto articula os aspectos agrários e agrícolas com os ecológicos, sob um olhar ambiental mais amplo, ou socioambiental, para melhor traçar essa possibilidade. Conforme Altieri (2002), a Agroecologia definida de forma mais ampla representa uma abordagem agrícola que incorpora cuidados especiais relativos ao ambiente, assim como aos problemas sociais, enfocando não somente a produção, mas também a sustentabilidade ecológica do sistema, integrando sistema de produção com ecossistema local.

Conforme Diegues (1996) os cientistas da Conservação, e conforme Altieri (2002) os cientistas da Agricultura convencional, reconhecem cada vez mais, que tem se trabalhado com uma abordagem reducionista, limitando as opções agrícolas e ambientais, trazendo assim consequências não planejadas, que tem gerado custos ambientais e sociais. AAgroecologia está do lado da vida em sua multiplicidade, aponta para a potencialização e evolução dinâmica da vida, na possibilidade de revitalização do território e assim num enfoque mais múltiplo e menos reducionista, considerando as relações entre ser humano e natureza. Trata como importante o conhecimento empírico de quem está lidando na prática com a terra. Tal aspecto é ressaltado na fala seguinte:

... então lá fora a gente não segue o nosso relógio biológico... porque sempre tem que seguir as normas lá, das empresas, das firmas onde a gente trabalha...Então aqui a gente segue mesmo a natureza mesmo da gente!!! (Acampado de Sebastião Lan gleba II, 2002).

Em documentos da IUCN ${ }^{10}$ de 1988 (apud DIEGUES, 1996), há uma primeira vinculação entre a manutenção da diversidade biológica e a diversidade cultural:

A destruição da vida selvagem e florestas hoje tem relativamente pouco a ver com as espécies em si, mas é decorrência das relações entre a população e a

${ }^{10}$ União Internacional para Conservação da Natureza. 
natureza e das relações entre as pessoas.

E avalia que até agora,

O movimento conservacionista foi liderado por naturalistas... Ainda que sua contribuição tenha sido essencial, eles foram incapazes de resolver os problemas básicos da conservação porque os fatores limitantes não são de ordem ecológica, mas principalmente politicos, econômicos e sociais. As opiniões para a conservação têm que ser procuradas entre os políticos, sociólogos rurais, agrônomos e economistas. Em última análise, os usuários dos recursos naturais locais são aqueles que tomam as decisões. (IUCN, 1988, apud DIEGUES, 1996)

Diegues (1996) enfatiza a importância do conhecimento das populações locais para assegurar a diversidade biológica, assim como Shiva (1992) chama atenção para o fato de que a biodiversidade não pode ser conservada a menos que, a diversidade seja tomada como a lógica da produção e que o desaparecimento dos meios de vida e de sustento das populações encontram-se intimamente ligado à erosão da biodiversidade. A prática da diversidade é a chave para a sua conservação. A experiência de muitos agricultores vai se dando no dia a dia em que a construção do sistema produtivo vai ocorrendo a partir do trato com a diversidade biológica. Em depoimento adiante, a agricultora mora em lote situado em área degradada com solo desestruturado, aonde não nascia sementes de nativas das ilhas de mata próximas, situação essa encontrada quando chegaram na terra. A partir do roçado e da melhoria da biomassa no solo, sementes de nativas arbóreas começaram a nascer. Há uma experiência no manejo da diversidade, conforme vemos no relato de acampada de Sebastião Lan gleba II (2002): "Eu faço assim em casa mesmo, sabe... prá gente... porque eu plantei pouco, é assim uma experiência... que eu fiz pra ver se vai dar."

A população do mico leão dourado aumentou para a estimativa de mil animais, tendo em 2001 nascido o milésimo animal (JORNAL DO BRASIL, 2001), sendo que desses mil animais, uma parte está na natureza e uma parte em cativeiro. Em 2003, a espécie passou da categoria criticamente ameaçada a espécie para ameaçada de extinção pela IUCN. Como em 1995 e 1997 foram instalados assentamentos no entorno da reserva, o aumento dos animais conviveu positivamente com a presença dos assentamentos de reforma agrária na região (Cambucaes em dezembro/1995 e Sebastião Lan em junho/1997). Logo, parece indicar que nesse período não houve pressão que resultasse em diminuição da população de mico leão dourado.

A consanguinidade na espécie pode não necessariamente responder aos altos investimentos com o seu manejo exógeno, feito a partir de cada vez mais intervenções de porte cada vez maior, tais como: reprodução em cativeiro em outro país, reintrodução na natureza, alimentação artificial, translocação de animais ameaçados e ainda mistura 
de animais para troca genética. Nada garante que essa espécie estará protegida da extinção. É preciso que existam animais na natureza com material genético novo, diversificado. Os animais de cativeiros tem uma bagagem genética limitada, partiram de um conjunto matriz limitado. Relata-se que a população residual do mico leão antes da criação da reserva era de cerca de 200 animais. Há possibilidade desses animais hoje se recuperarem e saírem da ameaça de extinção?

A existência de populações da espécie de mico leão em liberdade em convivência com as comunidades humanas, há pelo menos três gerações, ocorre no entorno imediato na região do Assentamento Cambucaes/Comunidade Olhos D'água (nas proximidades do Rio São João). Agricultores posseiros em suas terras praticam lavoura consorciada com frutíferas e mata nativa, uma agrofloresta produzindo laranja, café, tangerina, aipim, banana, e outras espécies. Segundo relatos, os micos circulam e se alimentam por toda a região que se encontra bem conservada. Nas matas no outro lado do entorno da reserva (nas proximidades do canal Aldeia Velha) encontram-se áreas potenciais de presença de micos, que podem se ligar por corredores ao longo da área chamada de brejão. Há fragmentos de mata no brejão que tem conexão com a reserva biológica e ocorrem indivíduos de mico leão dourado nessas áreas, protegidos, indicando a convivência com o entorno agrícola, bem como, a possibilidade da recuperação e possível contato daí para frente com outras manchas de mata, aumentando a conectividade e a possibilidade de novos cruzamentos. Os agricultores que lidam com a mata no dia a dia acompanham as transformações, como vê-se abaixo na fala de um agricultor assentado em Cambucaes, localidade de Olhos d'Água (2002): “Os bicho andam. Os mico andam isso tudo aí, come banana ali dentro uma porção, abacate quando tá maduro, eles comem ali na porta."

A ampliação da heterogeneidade genética na espécie, integrada com a dinâmica ecológica e social na região, pode levantar chances de mitigar a consanguinidade e apontar para um longo prazo sustentável geneticamente, ecologicamente e socialmente. É preciso recuperar a diversidade como um todo, pois há dentro da Reserva Biológica desequilíbrios ecológicos na cadeia alimentar que envolve o mico-leão, conforme informações junto ao Programa de Ecologia do mico-leão ${ }^{11}$, em que a extinção de predadores de topo de cadeia pode ter levado ao aumento de predadores de porte médio, o que já ocorreu com registro de predação de muitos indivíduos de mico-leão.

O que garante a possibilidade de uma espécie encontrar-se livre da extinção? É a construção de sustentabilidade ecológica. Não é só a presença da espécie "viva", se o seu ambiente está moribundo, com sinais de morte anunciada. E para tal é preciso de fato construir atividades socioambientais, com participação do entorno e das comunidades na recuperação ambiental.

O grande proprietário rural pode ter interesse no status ambiental, visto que encontra-

\footnotetext{
${ }^{11}$ Programa da ong Associação Mico Leão Dourado.
} 
se em decadência boa parte de suas atividades produtivas. Todavia, a consciência e os valores com base na prática e no modo de vida, está presente em atividades ligadas à uma agricultura de pequena produção, que tem princípios ecológicos e comunitários em sua base, como: a diversificação de culturas; o consórcio de espécies; a manutenção de nativas; a incorporação de árvores; e por conseguinte, a atração da biodiversidade, que poliniza e fertiliza o ambiente com sementes e regenera a dinâmica ecológica; podendo recuperar o solo, a vegetação, a fauna, e a trama de relações que faz desses ambientes tropicais ricos e produtivos (REIS, 1999). E sobretudo, com muitas oportunidades de uso, com funções ambientais necessárias e valiosas para a região e mais ainda para o futuro da biota - animais, plantas e seres humanos.

Podemos considerar duas experiências apontadas como importantes neste cenário para outras regiões. Conforme Pádua ${ }^{12}$ (2001) a conservação do mico-leão-preto ${ }^{13}$ motivo da criação do Parque Estadual do Morro do Diabo, SP, em remanescentes florestais do Pontal do Paranapanema, se tornou mais efetiva, na medida em que o projeto de conservação da espécie incorporou a participação direta dos agricultores das áreas próximas destes remanescentes, em grande parte beneficiários de projeto de assentamento rural na região ${ }^{14}$.

Na região noroeste de Minas Gerais, no município de Guarda-Mor, zona de entorno do Parque Estadual do Rio Doce, Mazzetto e Cavallini (2002) emitiram um parecer técnico de Viabilidade Ambiental da Fazenda Sacramento para fins de criação de projeto de assentamento rural e para subsidiar a decisão sobre o licenciamento ambiental prévio para implantação do respectivo projeto. $\mathrm{O}$ referido parecer técnico não aponta nenhum impedimento efetivo para o estabelecimento de um projeto de assentamento na área em questão. $\mathrm{O}$ assentamento rural de trabalhadores sem terra não é um empreendimento que necessariamente entra em choque direto com os interesses de conservação do entorno de áreas protegidas. Pelo contrário, foi qualificado e considerado um impedimento à expansão do perímetro urbano de Pingo D'água e também das monoculturas de eucaliptos de empresas na direção do Parque Estadual do Rio Doce, tornando, assim, mais efetiva a proteção da biodiversidade, através da recuperação de áreas degradadas e da ligação entre remanescentes florestais.

\footnotetext{
12 Prof. Dr. Cláudio Valladares Pádua, (do Ipê, Pontal Paranapanema, SP) em palestra no Congresso Nacional de Ecologia, 2001.

${ }^{13}$ Existem quatro espécies registradas de mico leão endêmicas das seguintes áreas transformadas em unidades de conservação: mico caiçara no Paraná (Parque Nacional do Superagui), sauim preto em São Paulo (Parque Estadual do Morro do Diabo), sauí vermelho no Rio de Janeiro (Reserva Biológica Poço das Antas), e sauim una na Bahia (Reserva Biológica de Una).

${ }^{14} \mathrm{~A}$ parceria entre os gestores do parque e os assentamentos do entorno foi retratada como um sucesso em matéria do Jornal do Brasil (2002).
} 


\section{Uso da terra e a viabilidade ambiental do Assentamento Sebastião Lan gleba II.}

O chamado brejão pode ser delimitado hoje pelos limites hídricos do Canal de Aldeia Velha (que é neste trecho limite da Rebio Poço das Antas) que encontra com o Canal de São João, e no trecho restante tem o seu limite dado pelo antigo leito do Rio Aldeia Velha. Com as obras de drenagem da década de 70 essa área teve alterado o curso do Rio Aldeia Velha para o atual canal Aldeia Velha, assim como o Rio São João para o respectivo canal de São João. Desde então, os antigos leitos dos rios foram abandonados. E essa área do brejão foi grilada pelo fazendeiro da área contígua, que arrendou para muitos arrendatários que plantaram primeiramente o arroz e depois principalmente aipim, batata doce e banana, com uso de máquinas e muitos insumos químicos. $\mathrm{O}$ arroz fracassou e o uso depois da área foi pouco otimizado e tampouco teve sucesso, tendo arrendatários e o próprio fazendeiro dívidas no banco até os dias atuais.

É extremamente relevante poder reconhecer o histórico de uso da terra na área e considerar o enorme passivo ambiental e social. Em 1997 a área foi ocupada por trabalhadores rurais sem terra. Hoje a área está ocupada com muitas famílias divididas nos lotes, aproveitados com base nos lotes dos arrendatários, que tem as valas e os canais de drenagem como os limites. $\mathrm{O}$ ambiente foi encontrado muito degradado pelas atividades agropecuárias, com acúmulo de veneno e condições de produtividade da terra bem reduzidas, o que vem sendo transformado, trazendo ganhos ecológicos a partir do manejo da pequena produção realizada pelos acampados:

O milho dela (da terra) aqui, você plantava ele, quando ele chegava desse tamanhozinho assim o pé dele torrava em baixo assim e quebrava! Hoje qualquer lugar que você quiser plantar milho aqui, 'cê tá colhendo...!! (Acampado de Sebastião Lan, gleba II, 2002)

Hoje acabou... quando acabou com o veneno, a terra retomou vida novamente! Quando nós chegamos prá cá, abóbora que eu plantei mais de dois mil cova e num vingou e ficou no pé que ela morreu! Já esses tempo agora, eu plantei cento e cinquenta pés de abóbora e colhi muita raça de abóbora!! Depois eu quero terra é prá trabalhá!! (Acampado de Sebastião Lan, gleba II, 2002)

A área chamada de brejão, lugar do Acampamento Sebastião Lan 2, é em grande parte coberta por vegetação rasteira, em grande extensão por sapé, com trechos de mata secundária por todo o antigo leito do rio Aldeia Velha e algumas ilhas de mata. Totaliza cerca de 1466 ha, com cobertura vegetal e uso da terra retratados abaixo: 


\begin{tabular}{|l|l|}
\hline Cobertura vegetal e uso da terra & Extensão \\
\hline Ilhas de mata (três fragmentos) & 47,6 ha \\
\hline $\begin{array}{l}\text { Mata secundária no antigo leito do } \\
\text { Aldeia Velha }\end{array}$ & 176,5 ha \\
\hline $\begin{array}{l}\text { Vegetação herbácea com plantios } \\
\text { mais recentes (sapé) }\end{array}$ & 317,9 ha \\
\hline Área de cultivos antigos e recentes & 924 ha \\
\hline
\end{tabular}

Fonte: UFF, 2002.

Quadro II. Cobertura Vegetal e Uso da Terra do Acampamento Sebastião Lan 2.

A região possui relevância para a manutenção de diversas populações de espécies silvestres viáveis no entorno e também no interior da Reserva Biológica de Poço das Antas, visto que é uma área prioritária para recuperação ambiental, de forma a permitir expansão de área para a biota silvestre e também minorar o efeito de borda potencializado pelos constantes incêndios nessa área degradada do entorno, na maioria por fazendas de gado. Essas propostas modificam a paisagem, diversificam e melhoram a qualidade dos habitats, num plano de organização espacial das áreas no entorno de unidades de conservação. Planos de manejo (como o citado do PERD/MG) e também indicações de cursos de capacitação em agrofloresta para os assentamentos do entorno da Reserva Biológica Poço das Antas (INCRA, 2001), tem indicado a necessidade de se implantar sistemas agroflorestais para esses casos e de forma participativa. Podemos acompanhar em relato abaixo a percepção à respeito do papel do Estado:

Então é onde eu penso se nós com estes cinco anos tivesse pelo menos um ano de ajuda do governo, do próprio Incra, da própria prefeitura, muitas vez, a reserva tava ainda mais protegida do que tá, porque nós tinha condições de proteger o entorno da reserva toda. Com árvore, com trator, com tombo, entendeu?! (Acampado de Sebastião Lan, gleba II, 2002)

É importante uma análise socioespacial e ecossistêmica ao considerarmos assentamentos rurais, ir além de métodos convencionais que reduzem a um ou outro aspecto do ambiente insatisfatoriamente (MAZZETTO, 2001). Apresentamos uma proposta preliminar de zoneamento ressaltando áreas básicas de uso e de conservação considerando a viabilidade para projeto de assentamento (ver quadro III). Precisarão ser recuperadas áreas que foram degradadas há pelo menos trinta anos, tais como as matas ciliares, bem como, a vegetação para totalizar a reserva legal em $20 \%$. Já existem experiências e manejos na área nesses cerca de oito anos dos agricultores sem terra, indicando o plantio de mata ciliar e manchas de mata com cultivos numa 
agrofloresta inicial que faz gradativamente a passagem da mata para a área de cultivo mais intensivo. Acampados no entorno do canal Aldeia Velha, no brejão, mostram empenho e assimilação da importância do cuidado ambiental, realizando cultivos associados à mata e em trechos necessários mantendo aceiros com o uso de tratores.

Quadro III. Zoneamento Agroecológico do Acampamento Sebastião Lan 2.

\begin{tabular}{|l|l|l|l|}
\hline $\begin{array}{l}\text { Cobertura Vegetal e Uso } \\
\text { da Terra }\end{array}$ & Discriminação & Extensão & $\begin{array}{l}\text { Grau de uso ou } \\
\text { conservação }\end{array}$ \\
\hline $\begin{array}{l}\text { Ilhas de mata (três } \\
\text { fragmentos) }\end{array}$ & Reserva Legal & 47,6 ha & $\begin{array}{l}\text { Preservação } \\
\text { integral }\end{array}$ \\
\hline $\begin{array}{l}\text { Mata secundária no antigo } \\
\text { leito do Aldeia Velha }\end{array}$ & Reserva Legal & 176,5 ha & $\begin{array}{l}\text { Preservação } \\
\text { integral }\end{array}$ \\
\hline $\begin{array}{l}\text { Vegetação herbácea com } \\
\text { plantios mais recentes (sapé) }\end{array}$ & $\begin{array}{l}\text { Área de manejo } \\
\text { agroflorestal e/ou } \\
\text { cultivo }\end{array}$ & 317,9 ha & $\begin{array}{l}\text { Uso restrito e/ou } \\
\text { intensivo }\end{array}$ \\
\hline $\begin{array}{l}\text { Área de cultivos antigos e e Área de manejo } \\
\text { recentes } \\
\text { agroflorestal e/ou } \\
\text { cultivo }\end{array}$ & 924 ha & $\begin{array}{l}\text { Uso restrito e/ou } \\
\text { intensivo }\end{array}$ \\
\hline Margem dos canais & $\begin{array}{l}\text { Área de recuperação } \\
\text { e Preservação } \\
\text { permanente }\end{array}$ & & $\begin{array}{l}\text { Preservação } \\
\text { integral }\end{array}$ \\
\hline
\end{tabular}

Fonte: UFF, 2002.

Parte da reserva legal, ao unir os dois maiores fragmentos, propiciará a conexão destes com a Reserva Biológica de Poço das Antas, o fragmento menor se conectará com a mata ciliar do Canal São João e também tem contato bem próximo com fragmentos de mata da fazenda Arizona. As áreas de preservação permanente são representadas por trechos ao longo dos canais São João e Aldeia Velha, que serão recuperados, utilizando-se agroflorestas, o que pode permitir o uso, o envolvimento da comunidade, sendo também mais rápido e mais eficiente para o processo de sucessão ecológica, de recuperação da dinâmica ecológica e da diversidade nos diferentes estágios sucessionais. As áreas de uso restrito comportarão manchas de capoeira em estágio mais avançado de recuperação, áreas de agroflorestas com manejo que vise favorecer espécies úteis e mantenha as espécies nativas. Assim, servirão também pelas funções ambientais, diminuindo o efeito de borda da Reserva Legal e da Reserva Biológica e ampliando a cobertura florestal da área do brejão. As áreas de agrofloresta podem circundar remanescentes florestais, de forma a incluir gradativamente frutíferas e outras arbóreas numa transição mata-agrofloresta-cultivo. As áreas de uso intensivo são os cultivos diversificados anuais.

Há receptividade na comunidade à propostas nesse sentido. Pode-se evidenciar acúmulo de experiência no local e de atividades realizadas. Aconteceram trocas de 
experiências entre acampados do brejão e assentados do Pontal de Paranapanema em visita técnica promovida pelo MST e AMLD em 2000; visita às experiências agroecológicas da Fazendinha Agroecológica Embrapa/RJ; participação de representante dos agricultores no Encontro Nacional de Agroecologia - UERJ/RJ (2002), troca de experiências agroflorestais dos agricultores de Paraty com os de Silva Jardim, RJ; orientação de agricultores de Paraty com larga prática em agrofloresta, que foram ao brejão realizar intercâmbios.

\section{Conclusão}

Os acampados tem um entendimento da legislação ambiental como uma barreira para o processo deles se consolidarem enquanto assentamento, e assim, se organizarem melhor frente aos parâmetros exigidos pela lei. Salientam o processo excludente em que as leis são conduzidas, o IBAMA e o INCRA não os inclui como parte do processo. E o caso dos trâmites do Termo de Ajustamento de Conduta em que o Ministério Público denunciou o INCRA, advertindo para os riscos de um assentamento ao lado da reserva. Causa grande estranhamento para os trabalhadores, pois entendem que sendo eles os que estão ali na terra, executores assim de muitas das medidas na prática, participar permite ir realizando a adaptação e a organização frente às normas exigidas.

Percebem ambigüidade na ação do INCRA e nem sempre é claro para eles que o órgão está defendendo os direitos dos trabalhadores. Esses aspectos vem reforçando a resistência e a organização deles para permanência na terra. No ano de 2005, completaram 8 anos de acampamento. Episódios anteriores junto ao órgão levaram à descrença e o projeto de permanecer nas terras do brejão é assim reafírmado.

O que impede o assentamento hoje é a Ação Civil Pública junto ao Ministério Público e alimentada pelo IBAMA. Reconhecem que o que está segurando o processo do assentamento são as exigências ambientais por parte do IBAMA: não usar fogo, não caçar e não usar agrotóxico. Acreditam e entendem que é plenamente possível agricultura e floresta juntos, e estranham a ação autoritária do IBAMA que não avalia o papel positivo que eles podem ter. Como usam a água do rio para consumo e alimentação, conseguem registrar épocas em que são despejados acima venenos e o processo de vigilância e denúncia que realizam se perde na burocracia, ou na falta de diálogo e troca entre a população e os órgãos. Já plantaram quatro mil árvores nas terras do brejão, e se perguntam sobre o IBAMA ter recuperado a área desmatada equivalente ao trecho do acampamento na reserva. Há uma relação diária de acompanhamento e contato com a terra, a mata, a água e um diagnóstico das transformações do ambiente é feita na experiência do dia a dia. O reconhecimento desse conhecimento prático é ausente nas práticas dos órgãos, desconsiderando-se um potencial de contribuições e de impactos positivos da população junto ao ambiente, um potencial desprezado de ação junto à reserva.

Percebe-se também que há inúmeros problemas ambientais no município como um todo, que não são tratados de forma interligada e nem mesmo se dirige a atenção para o conjunto destes. Em torno da vegetação e da água, a dinâmica ecológica evidencia 
a totalidade da problemática, tais como, o desmatamento nas serras, as estradas e as obras de intervenção vão acumulando dificuldades, causando cheias mais duradouras, assoreamento nos rios, assim como, o uso dos venenos nas propriedades se faz sentir nas baixadas com a diminuição da fauna do rio e também com a queda da qualidade da água. As várias causas da degradação ambiental e do impacto na biodiversidade não são levadas em conta para tratar o assunto. Medidas ambientais que pensem na conservação do ambiente como um todo e da relação da população com o ambiente não tem sido a tônica sinalizada pelas ações dos órgãos. Somente uma perspectiva socioambiental de tratamento científico, bem como, de políticas públicas, poderão dar o salto necessário para se considerar a região ambientalmente conservada num horizonte de sustentabilidade ecológica e social, e não somente tentativas de proteção isoladas, com foco reducionista que abarca uma única espécie, dentre tão rica sociobiodiversidade e dinâmica ecológica locais.

\section{REFORMA AGRÁRIA E MEIO AMBIENTE: INTERFACES DA FUNÇÃO SOCIAL E AMBIENTAL DA TERRA}

Resumo: O presente trabalho aborda o histórico das transformações e as várias intervenções do Estado na região do vale do Rio São João, RJ. Criou-se a Reserva Biológica de Poço das Antas IBAMA na década de $70 \mathrm{em}$ fazendas desapropriadas pelo INCRA para proteção de espécie de primata ameaçada de extinção (o sauí vermelho ou mico leão dourado). Na década de 90 criaram-se assentamentos de reforma agrária no entorno da reserva biológica. Resultou em conflito agrário e ambiental. O litígio ambiental foi conduzido na forma de ação civil pública pelo Ministério Público, entendendo que o assentamento é uma ameaça à reserva biológica. Está em jogo o debate da crise ambiental, do mito da natureza intocada, dos impasses da relação ser humano e natureza, bem como, das formas de convivência entre reforma agrária e meio ambiente, entre os sujeitos da luta pela terra e os sujeitos da luta pela preservação ambiental.

Palavras Chave: Reforma Agrária, Conservação, Agroecologia, Assentamento Rural.

AGRARIAN REFORM AND ENVIRONMENT: INTERFACES OF SOCIAL AND ENVIRONMENTAL LAND FUNCTION

Abstract: This article analyses the historical transformations and the State interventions in São João River Valley region, in Rio de Janeiro, Brazil. In the 70's it was created the Biological Reserve of Poço das Antas IBAMA in farms desapropriated by INCRA in order to protect a primate species in extinction threat (the red sauí or golden lion tamarin). In the 90's it was created agrarian reform rural settlements around the biological reserve. It has resulted in agrarian and environmental conflicts. Environmental litigation was conducted in a public civil action by Public Ministery, considering the settlement a menace to biological reserve. It is under discussion the environmental crisis, the untouchable nature myth, questions around human being and nature relation, as well as, close association between agrarian reform and environment, between land struggle and environmental preservation struggle.

Keywords: Agrarian Reform, Conservation, Agroecology, Rural Settlement. 


\section{BIBLIOGRAFIA}

ALTIERI, Miguel. (2002). Agroecologia - bases científicas para uma agricultura sustentável: Rio Grande do Sul: Ed. Agropecuária e ASPTA.

BINSZTOCK, Jacob. (1998). Capitalismo Autoritário e a Questão Ambiental no Vale do São João. In: Campo Aberto - o rural no estado do Rio de Janeiro. Rio de Janeiro: Ed. Contracapa.

BINSZTOCK, Jacob. (1993). Capitalismo Autoritário è a Questão Ambiental no Espaço Agrícola do Estado do Rio de Janeiro - Vale do São João. Tese de Titular do departamento de Geografia UFF.

BINSZTOCK, Jacob. (2001). O Fracasso da Agricultura Empresarial no Vale do São João. Anais do Seminário "O Estado do Rio no início do século XXI." Niterói: GGE/UFF.

BRASIL. (2002) SNUC - Sistema Nacional de Unidades de Conservação da Natureza: lei no9.985, de 18 de julho de 2000; decreto no 4.340, de 22 de agosto de 2002. 2.ed. Aumentada. Brasília: MMA/SBF.

CUNHA, Sandra. (1995). Impacto das Obras de Engenharia sobre o Ambiente Biofisico da Bacia do Rio São João. Rio de Janeiro: Ed. UFRJ.

DEAN, Warren. (1996). A Ferro e Fogo - a história e a devastação da mata atlântica. São Paulo: Ed. Cia das Letras.

DIEGUES, Antonio Carlos. (1996). O Mito Moderno da Natureza Intocada. São Paulo: Ed. Hucitec.

FERNANDEZ, Fernando. (2000). Efeitos da Fragmentação de Ecossistemas: a situação das unidades de conservação. Seminário sobre Unidades de Conservação Urbanas. Rio de Janeiro.

FUKS, M. (2001) Conflitos Ambientais no Rio de Janeiro - ação e debate nas arenas públicas. Rio de Janeiro: Ed.UFRJ.

INCRA. (2001). PDA Assentamento Sebastião Lan. Rio de Janeiro: UFRRJ.

JORNAL DO BRASIL. (2002) "Sem-terra e fazendeiros firmam parceria". JB, 24 de março de 2002, p.3-4.

JORNAL DO BRASIL. (2001) "Nasce o milésimo mico-leão-dourado". JB, 05 de abril de 2001, p.14.

KAGEYAMA, Paulo. (2003). Restauração e conservação de ecossistemas tropicais. In: Cullen Jr (orgs). Métodos de Estudos em Biologia da Conservação e Manejo da Vida Silvestre. Ed. Univ. Fed. Paraná.

PRIMACK, R.B. e E. RODRIGUES. (2001). Biologia da Conservação. Ed. Sinauer.

MAZZETTO, Carlos E. Silva. (2001). Análise Agroambiental de Imóveis para uma Reforma Agrária Sustentável (mimeo). Minas Gerais: INCRA.

MAZZETTO, Carlos E. Silva e CAVALLINI, Marcelo. (2002). Relatório Complementar sobre Viabilidade Ambiental da Fazenda Sacramento visando 
criação de um Projeto de Assentamento. Minas Gerais: INCRA, Superintendência Regional de Minas Gerais, Div.Técnica.

SHIVA, V. (1992). A Semente e a Roca de Fiar. Rio de Janeiro: Ed. ASPTA.

UFF GT ECOSOCIAL. (2002) Laudo multidisciplinar e termo de cooperação técnica para convivência harmoniosa de assentamentos rurais no entorno da Reserva Biológica de Poço das Antas coordenado por Madeira $\mathrm{F}^{\circ}$, Wilson; Britto Pereira, Mônica Cox de; Prata F ${ }^{\circ}$, Dario de Andrade \&. Ribeiro, Ana Maria Motta. Niterói, Silva Jardim e Casemiro de Abreu: UFF/MMA/MDA.

REIS, Ademir, et al. (1999). "Recuperação de Áreas Florestais Degradadas Utilizando a Sucessão e as Interações Planta-animal". Caderno no 14, Reserva da Biosfera da Mata Atlântica. São Paulo. 